\title{
Research of the Classification Model Based on Dominance Rough Set Approach for China Emergency Communication
}

\author{
Fan Zifu, Sun Hong, and Wang Lihua \\ College of Economic Management, Chongqing University of Posts and Telecommunications, Chongqing 400065, China \\ Correspondence should be addressed to Fan Zifu; fzfboy@163.com
}

Received 10 November 2014; Accepted 16 February 2015

Academic Editor: Julien Bruchon

Copyright ( 2015 Fan Zifu et al. This is an open access article distributed under the Creative Commons Attribution License, which permits unrestricted use, distribution, and reproduction in any medium, provided the original work is properly cited.

\begin{abstract}
Ensuring smooth communication and recovering damaged communication system quickly and efficiently are the key to the entire emergency response, command, control, and rescue during the whole accident. The classification of emergency communication level is the premise of emergency communication guarantee. So, we use dominance rough set approach (DRSA) to construct the classification model for the judgment of emergency communication in this paper. In this model, we propose a classification index system of emergency communication using the method of expert interview firstly and then use DRSA to complete data sample, reduct attribute, and extract the preference decision rules of the emergency communication classification. Finally, the recognition accuracy of this model is verified; the testing result proves the model proposed in this paper is valid.
\end{abstract}

\section{Introduction}

As an important foundation for the national economy industries, emergency communication is directly related to the smooth communication when the accident occurs, affecting the timely delivery of important information and the favoring progress of the emergency communication guarantee. However, the classification of emergency communication level is significant prerequisite for emergency communication guarantee [1]. However, the quantitative research on classification of emergency communication level is poor in China; the division of response levels in emergency communication support plan is based on the degree of influence on communication infrastructure caused by accident. So, the division of response levels in emergency communication support plan is not fit for the accident with different types and classes and need to build a set of new emergency communication classification criteria based on nature and extent of accident.

Currently, the popular classification methods contain the analytic hierarchy process (AHP), cluster analysis, dynamic fuzzy analysis method, and naive Bayes, decision tree, logistic regression analysis, neural networks, rough sets, and other classification methods based on data mining. Thereinto, rough set (RS) can deal with imprecise inconsistent and incomplete information effectively, and don't rely on future knowledge during the learning process (such as probability distribution in Bayesian and the membership in fuzzy set), so it is more objective in the description and disposition of the problem with the uncertainty. Since proposed by Pawlak in 1982 [2], rough set developed quickly from many machine learning study theories and has been widely applied in machine learning, medical diagnostic, market decision making, information security, and many other fields in recent years. In order to process information systems with continuous attributes and dominance relations, Greco et al. [3-5] proposed the dominance rough set approach (DRSA). In this method, the indiscernibility relation is replaced by the dominance relation and generates the decision rules in the form of "if conditions, then decision" through upward and downward union of classes. On one hand, this method considers future knowledge (i.e., preference information) of decision makers; on the other hand, the rules in rough set are suitable for decision makes to execute the decision-making behavior. What is more, RS can only conduct the attributes without dominance relation, while DRSA allows dealing with any kind of information including the continues data with the dominance relation and the attributes without dominance relation [6]. The attributes 
of classification for emergency communication in this paper have the dominance relation like communication support number, communication block length, and so forth and also have the attributes without preference dominance such as accident objective factors and accident type. So, we choose the DRSA theory to complete data, discretize, reduct attribute and extract preference decision rules in China emergency communication classification model. The research results can provide emergency communication support by optimizing the existing emergency communication support plans and help government departments to determine the emergency communication level of accident scientifically.

\section{Methods}

The rough set theory, firstly introduced by Pawlak in 1982, is a valuable mathematical tool for dealing with vagueness and uncertainty [7]. For a long time, the use of the rough set approach and other data mining techniques was restricted to classification problems where the preference order of the evaluations was not considered. This is due to the fact that this method cannot handle inconsistencies that occur as a result of the violation of the dominance principle [8]. In order to deal with this kind of inconsistency, it was necessary to make a number of methodological changes to the original rough set theory. Greco et al. [9] proposed an extension of the rough set theory based on the dominance principle that would permit it to deal with inconsistency. This method is mainly based on the substitution of the indiscernibility relation for a dominance relation in the rough approximation of decision classes. It is more general than the classic functional or relational model and is more understandable for users because of its natural syntax [8]. The basic concepts of DRSA are described in the following [10].

A data table is in the form of a 4-tuple information system $S=(U, Q, V, f)$, where $U$ is a finite set of objects (universe), $Q$ is a finite set of attributes/criteria, $V q$ is the domain of the attribute/criterion $q, V=\bigcup_{q \in Q} V q$, and $f: U \times Q \rightarrow V$ is a total function such that $f(x, q) \in V q$ for each $x \in U$, $q \in Q$, called the information function. The set $Q$ is usually divided into set $C$ of condition attributes and set $D$ of decision attributes.

Let $\geq q$ be an outranking relation to $U$ with reference to criterion $q \in Q$, such that $y \geq q^{z}$ means that " $y$ is at least as good as $z$ with respect to criterion $q$." It is said that object $z P$-dominates object $y$ with respect to $P \subseteq F$ (denotation $\left.z D_{p} y\right)$, if $z \geq{ }_{q} y$ for all $q \in P$, and $D_{p}=\cap_{q} \in_{p} \geq_{q}$, then the dominance relation $D_{P}$ is a partial preorder. Given $P \in C$ and $z \in U$, let

$$
\begin{aligned}
& D_{p}^{+}(y)=\left\{z \in U: z D_{p} y\right\}, \\
& D_{p}^{-}(y)=\left\{z \in U: y D_{p} z\right\}
\end{aligned}
$$

represent the $P$-dominating set and the $P$-dominated set with respect to $z$, respectively.

Let $\mathrm{Cl}=\left\{\mathrm{Cl}_{t}, t \in T\right\}, T=\{1, \ldots, n\}$ be a set of classes of $U$ such that each $x \in U$ belongs to one and only one class $\mathrm{Cl}_{t} \in \mathrm{Cl}$. We assume that all $r, s \in T$, such that $r>s$, and each element of $\mathrm{Cl}_{r}$ is preferred to each element $\mathrm{Cl}_{s}$. In other words, if $\geq$ is a comprehensive outranking relation on $U$, then it is supposed that $\left[x \in \mathrm{Cl}_{r}, y \in \mathrm{Cl}_{s}, r>s\right] \Rightarrow x>y$, where $x>y$ means $x>y$ and not $y>x$.

We can define unions of classes relative to a particular dominated or dominating class; these unions of classes are called upward and downward unions of classes and are defined, respectively, as

$$
\begin{gathered}
\mathrm{CL}_{i}^{\geq}=\bigcup_{t \geq i} \mathrm{CL}_{t} \quad(i=2,3, \ldots, n), \\
\mathrm{CL}_{i}^{\leq}=\bigcup_{t \leq i} \mathrm{CL}_{t} \quad(i=1,3, \ldots, n-1) .
\end{gathered}
$$

Supposing that $X$ represents both $\mathrm{CL}_{t}^{\geq}$and $\mathrm{CL}_{t}^{\leq}, E_{p}(y)$ represents $D_{p}^{+}(y)$ and $D_{p}^{-}(y)$. The $P$-lower and $P$-upper approximations of $X$, with respect to $P \in C$, are refined as

$$
\begin{gathered}
\underline{P}(X)=\left\{y \in U: E_{p}(y) \subseteq X\right\}, \\
\bar{P}(X)=\bigcup_{y \in X} E_{p}(y) .
\end{gathered}
$$

The $P$-boundaries ( $P$-doubtable region) of $X$ are defined as

$$
\operatorname{Bnd}(X)=\bar{P}(X)-\underline{P}(X) \text {. }
$$

The ratio

$$
\gamma_{p}(\mathrm{CL})=\frac{\operatorname{card}\left(U-\left(\bigcup_{t \in T} \operatorname{Bnp}(X)\right)\right)}{\operatorname{card}(U)}
$$

defines the quality of approximation of the classification CL by means of the criteria from set $P \subseteq F$, or, briefly, the quality of classification. This ratio expresses the proportion of all $P$ correctly classified objects - that is, all of the nonambiguous objects to all of the objects in the data table. Every minimal subset $P \subseteq F$ such that $\gamma_{P}(\mathrm{Cl})=\gamma_{f}(\mathrm{Cl})$ is called a reduction of $F$ with respect to $\mathrm{Cl}$ and is denoted by $\operatorname{RED}_{\mathrm{Cl}}(P)$. Again, a data table may have more than one reduct. The intersection of all of the reductions is known as the core, denoted by $\mathrm{CORE}_{\mathrm{Cl}}$.

In dominance rough set, deterministic rules are derived from class set $X$ of the lower approximation rules. The following two types of decision rules can be considered:

$$
\begin{gathered}
\text { if } \begin{aligned}
& f_{i 1}(y) \geq t_{i 1} \wedge \cdots \wedge f_{i p}(y) \geq t_{i p} \wedge f_{i(p+1)}(y) \\
&=t_{i(p+1)} \wedge \cdots \wedge f_{i z}(y)=t_{i z} \\
& \text { then } x \in \mathrm{cl}_{t}^{\geq} \quad(t=1, \ldots, n-1) \\
& \text { if } f_{i 1}(y) \leq t_{i 1} \wedge \cdots \wedge f_{i p}(y) \leq t_{i p} \wedge f_{i(p+1)}(y) \\
&=t_{i(p+1)} \wedge \cdots \wedge f_{i z}(y)=t_{i z} \\
& \text { then } x \in \mathrm{cl}_{t}^{\leq} \quad(t=1, \ldots, n-1) .
\end{aligned}
\end{gathered}
$$

Among them, $f_{i 1}, \ldots, f_{i}$ indicate condition attributes with dominance relation. $f_{i(p+1)}, \ldots, f_{i z}$ indicate condition attributes without dominance relation. $t_{i j}$ represents the attribute value of $f_{i j}$. 


\section{Classification Model of Emergency Communication}

The construction of emergency communication classification model is mainly divided into two phases: index extraction and data mining based on dominance rough set approach; the detailed construction steps are described as follows.

3.1. Construction of Classification Index System. Choosing which kind of indexes as a study variable has a great influence on the accuracy and reliability of the model. According to "General emergency plan national sudden public events of China," "National Communications Security Emergency Plan of China" [11], and the literature [12-19] and experts' advice, combined with the emergency communication characteristics of accident, emergency communication classification index system is divided into 20 indexes and four dimensions with emergencies objective factors, communication networks damaged, the emergency communication resources, and social and other factors, as shown in Table 1.

The definition and description of indexes are as follows.

(1) Communication Network Damage (A). This index refers to the network losses caused by accident. In general, communication networks can be divided into lines and equipment. In addition, the traffic increases sharply after the occurrence of accident and can cause severe communication network congestion and even network paralysis. Therefore, communication network damage in this paper is divided into traffic congestion situation (A1), line damage (A2), and communication facilities damage (A3).

Traffic congestion situation (A1) refers to the network congestion caused by traffic increase sharply after the incident occurred. This index assigns that it is 0 when there is no traffic congestion, and it is 1 when the network congestion occurs caused by traffic increase sharply. Line damage (A2) refers to the network communication line damage caused by accident. It can be measured from the damaged line length and range. Among them, the damaged line assigns that it is 1 if the damage line is provincial transmission line of, it is 2 if the damage line is Interprovincial transmission line, it is 3 if the damage line is the transmission line within a city's local area network, and it is 4 if the damage line is transmission line within a county. Communication facilities damage (A3) refers to the damage situation of communication point, rod, base station, and communication hub building caused by accident. Among them, the damaged bureau (including transfer boxes, junction boxes, and small communication rooms except communication hub building), rod, and base station are represented by detailed figures. The damaged communication hub building is assigned as follows: a country's communication hub building is 1 , a province's communication hub building is 2 , and a city's communication hub building is 3 .

(2) Accident Objective Factors (B). This index is used to describe the objective conditions when accident has occurred. In this paper, it will be defined as following twolevel indexes: emergency type (B1), emergency time (B2),
TABLE 1: Classification index system of emergency communication.

\begin{tabular}{ll}
\hline Code & Index \\
\hline & Communication Network Damage \\
A1Traffic Congestion Situation \\
A2Line Damage \\
A21Light (electric) Line Damage \\
A22LineDamage Range \\
A3Communication Facilities Damage \\
A31Bureau and Rod Damage \\
A32Base Station Damage \\
A33Communications Hub Building Damage \\
Accident Objective Factors \\
B1Accident Type \\
B2Accident Time \\
B3Affected Population \\
B4Accident Region \\
B5Accident Response Level \\
B6Directing and Coordinating Organizational Hierarchy \\
B Emergency Communication Resource \\
C1Emergency Communication Equipment \\
C11Emergency Communication Vehicles \\
C12Satellite Phone \\
C13Emergency Vehicles \\
C14Oil Engine \\
C2Communication Guarantee Number \\
Social Factors \\
D1Death Toll \\
D2Communication Block Length \\
\hline
\end{tabular}

affected population (B3), emergency region (B4), emergency response level (B5), and directing and coordinating organizational hierarchy (B6).

Accident type (B1) defines natural disasters, accidents disasters, public health events, social security events, and communication guarantee in the special period. Among them, communication guarantee in the special period is proposed by emergency communication tasks in "National Communications Security Emergency Plan of China" including some activities which require communication support, such as major sporting events and outdoor cultural activities. Accident time (B2) refers to the time the accident occurred. Generally, the destructiveness caused by accident occurring in the night is bigger. Therefore, if accident occurs from 7:00 to 12:00 and from 13:00 to 23:00, it is assigned to 1 . If accident occurs from 12:00 to 13:00 and from 23:00 to $7: 00$, it is assigned to 2 . Communication guarantee in the special period (in the whole day) is assigned to 3 . Affected population (B3) refers to the number of people caused by the accident. Accident region (B4) is the area where accident happens. This index is assigned as the following: 1 on behalf of several provinces, 2 on behalf of several cities within one province, 3 on behalf of several counties, and 4 on behalf of a single county. Accident response level (B5) refers to the whole 
emergency response level for the accident after it occurs. This index is assigned by the emergency response level of accident directly. Directing and Coordinating Organizational Hierarchy (B6) refers to the level of working organization after the accident occurs, which starts up the emergency response, schedules the emergency supplies, and implements emergency rescue. This index is assigned as the following: national level is 1 , several ministries and provinces joint command level is 2 , single ministry or province command level is 3 , and the others is 4 .

(3) Emergency Communication Resource (C). This index refers to communication resources needed for emergency rescue process after accident occurs, which is specifically divided into emergency communication equipment (C1) and communication guarantee number (C2).

Emergency communication equipment $(\mathrm{C} 1)$ refers to emergency communication equipment needed for supporting damaged communication network after accident occurs, such as emergency communication vehicles, satellite phones, and oil engine used to provide power for such equipment. Communication guarantee number (C2) refers to the number of the people of attending emergency communication guarantee work after accident occurs.

(4) Social Factors (D). This index refers to the influence situation caused by the accident, such as death, communication blockade, and economic losses. It is divided into death toll (D1), communication blockade length (D2), and economic loss (D3).

Death toll (D1) is the sum of population who lost their lives in the disaster area caused by accident. Communication blockade length (D2) refers to the time from the start of communication blockade to the full restoration of communication during the period in which accident occurs. Economic loss (D3) refers to many economic losses caused by accident, including the following two aspects: one is the direct economic loss including the cost of personal rescue and the properties damaged by accident. Another is the value calculated with the market price for destruction and lost; thereinto, Another is the indirect economic loss on destruction calculated with the market price, such as the house construction destruction, public facilities damage and the cost of labor or materials for repairing needed.

3.2. Establishment of Discriminant Knowledge Expression System. Assume that the system of emergency communication classification is in the form of a 4-tuple information system $S=(U, Q, V, f)$, where $U$ is a finite set of objects (unverse) and $Q$ is a finite set of attributes and is usually divided into set $C$ of condition attributes and set $D$ of decision attributes. In this paper, $F=$ accident objective factors, communication networks damaged, emergency communication resources, social factors $\}$ and $G=\{1,2,3,4\} . V$ is attributes corresponding range, $f: U \times A \rightarrow V$ is a total information function which gives a value to each classification object property.

3.3. Sample Selection and Data Collection. In this paper, the sample used 60 accident cases which occurred during
2008-2013 and launched the emergency communications support plan. Due to the emergency communications professional database systems are absent in China [20]; data procurement approach is the news of domestic telecommunications industry website and some international disaster database in this paper. Among them, the indexes of communication network damaged, emergency communications resources are from the emergency communications reports of MIIT official website and "natural disaster emergency communications support tracking reports" of Information Industry Network in China. The indexes of emergencies objective factors and social factors are from the following disaster databases: EM-DAT database, USGS earthquake database, Chinese marine disasters bulletin, and the seismic data management and service system in Chinese Earthquake Networks Center.

\subsection{Establishment of Initial Classification Decision Table.} After getting the sample data, we will establish the initial classification decision table, whose rows refer to accident and whose columns refer to the different attributes or criteria. Attributes are divided into condition attributes and decision attributes (different levels of emergency communication which are caused by accident). Among them, the condition attributes are divided into criteria with preference relations and conventional properties with no preference. The form of a data table is by means of collecting different attributes in various accidents. By matching news reports and disaster databases, we can construct a two-dimensional decision table form as incomplete decision information table (limited space, only a part) shown in Table 2 .

3.5. Data Preprocessing. There are two types of attributes including qualitative attributes and quantitative attributes; DRSA only handles data, so it should transfer the qualitative attributes into the data after attributes assignment. Because there are some qualitative indexes, we need attribute assignment to these qualitative indexes for processing with dominance rough set approach. As shown in Table 1, if the traffic obviously increases in one accident, the index of traffic congestion (A1) of this accident will be assigned to 1, or else assigned 0 . Meanwhile, mean/mode method was applied to fill data for the absent data which exists in the data collection (i.e., the symbol “*” in the Table 2 ). We can obtain a selfcontained decision table after attribute assignment and data complete.

3.6. Attribute Reduction and Rule Generating. Greco proposed a DOMLEM algorithm for extracting a set of relatively small number, complete and non-redundant decision rules from learning data sets. Currently, the DOMLEM algorithm has been integrated into the JMAF (intelligent decision analysis system based on dominance rough set approach exploited by Slowinski of Polish Academy of Sciences). Therefore, we use JMAF software for attribute reduction and rule extraction in this paper. Then, select and filter the rules based on the support degree, get the decision rule base of emergency communication classification. 
TABLE 2: The initial classification decision table.

\begin{tabular}{ccccccccccc}
\hline$U$ & A1 & A21 & A22 & $\ldots$ & C14 & C2 & D1 & D2 & D3 & E \\
\hline 1 & 1 & $*$ & $*$ & $\ldots$ & 44 & 140 & $*$ & & $*$ & 20 \\
2 & 1 & $*$ & $*$ & $\ldots$ & 113 & 334 & $*$ & 4 & 1.3 & 1 \\
3 & 1 & 35 & 1 & $\ldots$ & 476 & 1500 & 3 & 34 & 14.8 & 1 \\
4 & 1 & $*$ & 3 & $\ldots$ & 21 & 300 & $*$ & 9 & 7.6 & 2 \\
5 & 1 & 2869 & 2 & $\ldots$ & 774 & 3896 & 198 & 61 & 68 & 1 \\
6 & 0 & 1070.5 & 1 & $\ldots$ & 652 & 1319 & 81 & 32 & 10 & 4 \\
7 & 0 & $*$ & 1 & $\ldots$ & 40 & 100 & 7 & 21 & 0.1 & 2 \\
$\vdots$ & $\vdots$ & $\vdots$ & $\vdots$ & $\vdots$ & $\vdots$ & $\vdots$ & $\vdots$ & $\vdots$ & $\vdots$ \\
\hline
\end{tabular}

${ }^{*}$ indicates missing data.

3.7. Accuracy Testing. According to the decision rule base, we classify the data samples again and test the accuracy of model of this model.

Finally, government departments or specialists determine the final level of emergency communication according to the preference decision rules in decision rule base.

The whole process is shown in Figure 1.

\section{Results and Discussion}

4.1. Quality of Approximation. The initial decision table is used to fill the data by mean/mode method and get a complete two-dimensional decision table. According to the definition of dominance rough set approach, we can get the quality of approximate of each combined category:

$$
\begin{gathered}
\mathrm{CL}_{4}^{\leq}, \mathrm{CL}_{2}^{\leq}, \mathrm{CL}_{3}^{\geq}, \mathrm{CL}_{1}^{\geq}=1 \\
\mathrm{CL}_{3}^{\leq}=0.917 \\
\mathrm{CL}_{2}^{\geq}=0.947 .
\end{gathered}
$$

Approximation quality being higher, the overall level of approximation quality is $96.7 \%$. It is explained that the condition attributes selected in this paper are comprehensive and can get accurate classification results.

4.2. Results of Attribute Reduction. Using the different matrix with dominance relation to reduct, we can get the following 8 reduction results and 11 core attributes $\{\mathrm{A} 1, \mathrm{~A} 32, \mathrm{~B} 2, \mathrm{~B} 3$, B4, B5, B6, C11, C14, C2, D1\}, which represent separately the traffic congestion situation, base station damage, accident time, affected population, accident region, accident response level, directing and coordinating organizational hierarchy, emergency communication vehicles, oil engine, communication guarantee number, and economic loss.

4.3. Discrimination Rule Base. Using DOMLEM algorithm we can obtain 44 deterministic decision rules from 60 samples in total. Because of a larger number of rules, we select 29 deterministic rules which are supported higher than 5 to form the discrimination rule base. It is shown in Table 3.

From Table 3, we can see that the level 1 of emergency communication discrimination rules are 4, 7 rules for at least
2. 8 rules for at most 2, 6 rules for at least 3, 3 rules for at most 3,1 rule for level 4 .

4.4. Model Accuracy. When we classify these 60 cases again used the classification rules proposed in this paper, it is found that the former four level 3 is misjudged as level 2, one level 2 is misjudged as level 3, one level 1 is misjudged as level 2. The overall model accuracy is $90 \%$, which illustrates that the model has strong ability to learn and can more accurately identify the level of emergency communication.

According to the rules above, there are some conclusions as follows:

(1) The influence scope of accident plays a greater role in the decision of emergency communication level. For example, if accident causes traffic to increase sharply, needing more than one ministry or province joint command to deal with this accident, the level of emergency communications is 1 (rule 3 ). If traffic is not increase sharply, directing and coordinating organizational hierarchy is less than one ministry or province, the ultimate economic loss is no more than 161.4 billion yuan, the highest level of emergency communications at most 2 (rule 27). If the affected area is for multiple cities and communication guarantee number is more than 150000, the level of emergency communication is at least 3 (rule 13). When the accident affected area is only within a country, at the same time, the directing and coordinating organizational hierarchy is less than one ministry or province and the bureau and rod damage is less than 13400 , the level of emergency communication is 4 (rule 18).

(2) Damaged extent of accident to the communication infrastructure has a large impact on emergency communications level. For example, directing and coordinating organizational hierarchy is less than one ministry or province and the bureau rod and damage is up to 43900, the level of emergency communication is at most 2 (rule 24). When base station damage is less than 13400, emergency communication guarantee number is less than 42700 , directing and coordinating organizational hierarchy is less than one ministry or 


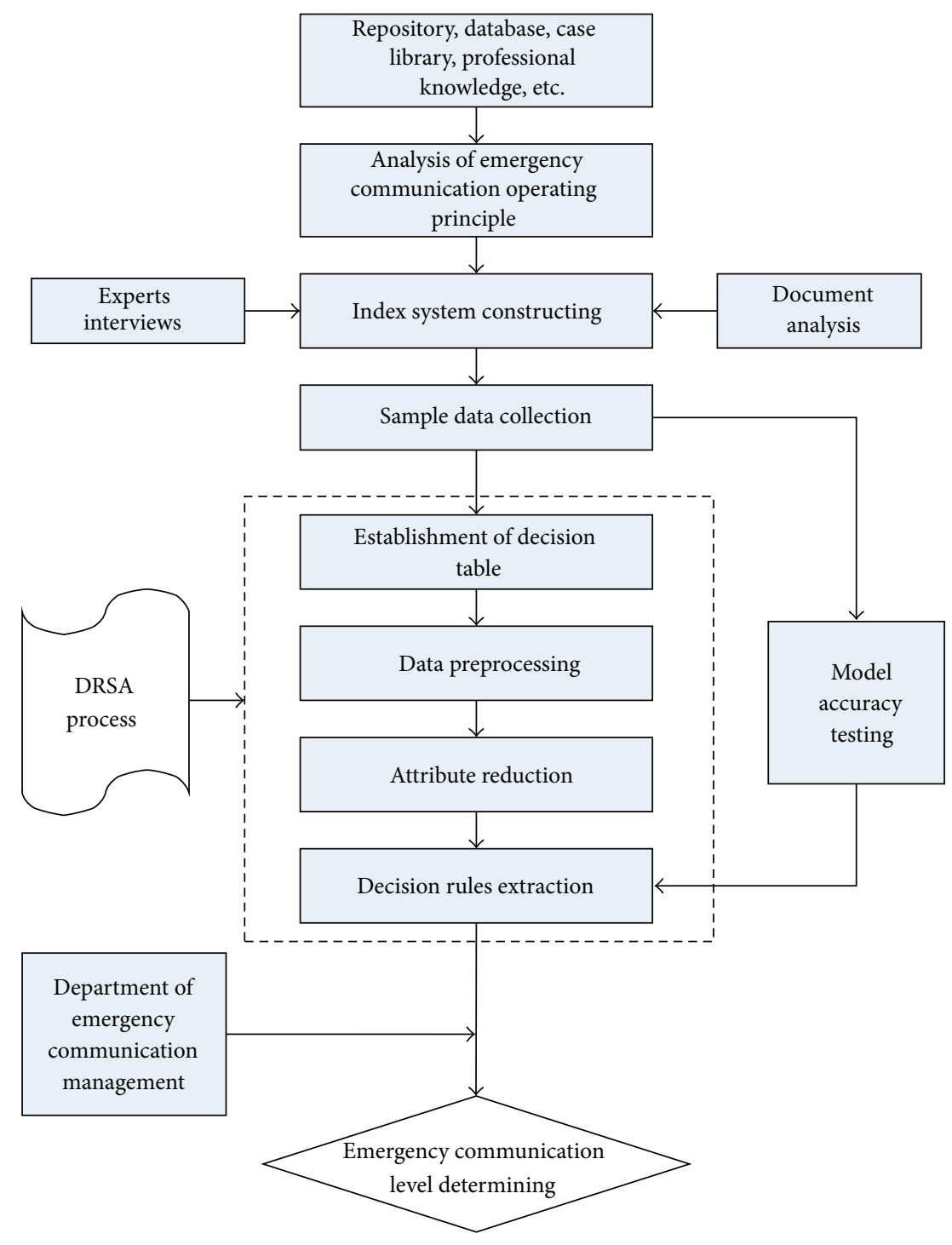

FIgURE 1: Emergency communication classification model.

province, the level of emergency communication is at most 3 (rule 20).

(3) Emergency communication resource has a definite influence on emergency communication level. For example, if directing and coordinating organizational hierarchy is several ministries and provinces joint command level, satellite phones used for accident are at least 2000, the level of emergency communication is at least 2 (rule 6). If multiple cities are affected by accident, emergency communications vehicles are at least 1600 , and emergency communication guarantee numbers are more than 43600 , the level of emergency communication is at least 3 (rule 15).

When accident occurs, emergency communication management department or specialists can refer to the preference decision rules of this model, focus on 11 core indexes, and determine the level of emergency communication finally.

\section{Conclusion}

In this paper, we proposed a new classification model of emergency communication based on dominance rough set approach, in which we can use the attribute reduction ability of dominance rough set approach theory to excavate key attributes from a large amount of raw data. Then, we conclude the correspondingly discriminate rules of the four levels in emergency communication by this classification model. According to the decision-making level range in the decision rules, combined with the core attributes, the department of emergency communication management can determine the level of emergency communication finally. This model can improve the scientificity of emergency communication classification and avoid the subjectivity of emergency communication classification in China. At the same time, the model accuracy is as high as $90 \%$.

The classification of emergency communication is throughout the whole accident, including accident 
TABLE 3: Discrimination rule base.

\begin{tabular}{|c|c|c|c|}
\hline Rule number & Conditions & Decision & Supporting number \\
\hline 1 & $(\mathrm{~B} 6<=2) \&(\mathrm{C} 14>=199800.0) \&(\mathrm{D} 2>=14400.0)=>(\mathrm{E}<=1)$ & Level 1 & 5 \\
\hline 2 & $(\mathrm{~A} 1>=1) \&(\mathrm{~B} 3>=3542000.0) \&(\mathrm{C} 13>=10200.0)=>(\mathrm{E}<=1)$ & Level 1 & 5 \\
\hline 3 & $(\mathrm{~A} 1>=1) \&(\mathrm{~B} 6<=2) \Rightarrow(\mathrm{E}<=1)$ & Level 1 & 5 \\
\hline 4 & $(\mathrm{~A} 31>=54200.0) \&(\mathrm{D} 2>=9600.0) \&(\mathrm{D} 3>=19043.0) \Rightarrow(\mathrm{E}<=1)$ & Level 1 & 5 \\
\hline 5 & $(\mathrm{~A} 31>=1954600.0)=>(\mathrm{E}<=2)$ & At least 2 & 5 \\
\hline 6 & $(\mathrm{~B} 6<=2) \&(\mathrm{C} 12>=2000.0) \Rightarrow(\mathrm{E}<=2)$ & At least 2 & 15 \\
\hline 7 & $(\mathrm{~B} 6<=2) \&(\mathrm{D} 2>=3500.0)=>(\mathrm{E}<=2)$ & At least 2 & 13 \\
\hline 8 & $(\mathrm{~B} 3>=2.5 \mathrm{E} 8)=>(\mathrm{E}<=2)$ & At least 2 & 8 \\
\hline 9 & $(\mathrm{~B} 4<=2) \&(\mathrm{~B} 5<=2)=>(\mathrm{E}<=2)$ & At least 2 & 7 \\
\hline 10 & $(\mathrm{~A} 1>=1) \&(\mathrm{D} 1>=196786.0)=>(\mathrm{E}<=2)$ & At least 2 & 6 \\
\hline 11 & $(\mathrm{~A} 22<=0) \&(\mathrm{~B} 4<=2) \&(\mathrm{C} 13>=2002033.0) \&(\mathrm{C} 2>=53700.0) \Rightarrow>(\mathrm{E}<=2)$ & At least 2 & 6 \\
\hline 12 & $(\mathrm{~A} 21>=17369.0) \&(\mathrm{~B} 4<=2)=>(\mathrm{E}<=3)$ & At least 3 & 13 \\
\hline 13 & $(\mathrm{~B} 4<=2) \&(\mathrm{C} 2>=150000.0)=>(\mathrm{E}<=3)$ & At least 3 & 27 \\
\hline 14 & $(\mathrm{D} 1>=196786.0) \&(\mathrm{D} 3>=760.0)=>(\mathrm{E}<=3)$ & At least 3 & 13 \\
\hline 15 & $(\mathrm{~B} 4<=2) \&(\mathrm{C} 11>=1600.0) \&(\mathrm{C} 2>=43600.0) \Rightarrow(\mathrm{E}<=3)$ & At least 2 & 26 \\
\hline 16 & $(\mathrm{~B} 4<=2) \&(\mathrm{~B} 6<=3) \&(\mathrm{C} 14>=281206.0)=>(\mathrm{E}<=3)$ & At least 3 & 19 \\
\hline 17 & $(\mathrm{D} 2>=3575.0) \&(\mathrm{D} 3>=19043.0)=>(\mathrm{E}<=3)$ & At least 3 & 11 \\
\hline 18 & $(\mathrm{~A} 32<=13400.0) \&(\mathrm{~B} 4>=4) \&(\mathrm{~B} 6>=3)=>(\mathrm{E}>=4)$ & Level 4 & 5 \\
\hline 19 & $(\mathrm{C} 2<=8300.0)=>(\mathrm{E}>=3)$ & At most 3 & 6 \\
\hline 20 & $(\mathrm{~A} 32<=13400.0) \&(\mathrm{~B} 6>=3) \&(\mathrm{C} 2<=42700.0) \Rightarrow>(\mathrm{E}>=3)$ & At most 3 & 10 \\
\hline 21 & $(\mathrm{~A} 31<=508700.0) \&(\mathrm{C} 11<=1500.0) \&(\mathrm{C} 2<=131900.0)=>(\mathrm{E}>=3)$ & At most 3 & 5 \\
\hline 22 & $(\mathrm{C} 2<=25800.0)=>(\mathrm{E}>=2)$ & At most 2 & 12 \\
\hline 23 & $(\mathrm{~B} 6>=2) \&(\mathrm{D} 3<=116.0)=>(\mathrm{E}>=2)$ & At most 2 & 20 \\
\hline 24 & $(\mathrm{~A} 31<=43900.0) \&(\mathrm{~B} 6>=3)=>(\mathrm{E}>=2)$ & At most 2 & 21 \\
\hline 25 & $(\mathrm{~B} 2=2) \&(\mathrm{~B} 6>=2) \&(\mathrm{D} 3<=960.0)=>(\mathrm{E}>=2)$ & At most 2 & 5 \\
\hline 26 & $(\mathrm{~B} 2=2) \&(\mathrm{D} 1<=7900.0)=>(\mathrm{E}>=2)$ & At most 2 & 7 \\
\hline 27 & $(\mathrm{~A} 1<=0) \&(\mathrm{~B} 6>=3) \&(\mathrm{D} 3<=16140.0)=>(\mathrm{E}>=2)$ & At most 2 & 21 \\
\hline 28 & $(\mathrm{~A} 22>=3) \&(\mathrm{D} 3<=1000.0)=>(\mathrm{E}>=2)$ & At most 2 & 7 \\
\hline 29 & $(\mathrm{~A} 1<=0) \&(\mathrm{~A} 22>=1) \&(\mathrm{D} 2<=5900.0)=>(\mathrm{E}>=2)$ & At most 2 & 6 \\
\hline
\end{tabular}

monitoring, early warning, emergency response, and post-evaluation. Emergency communications classification model based on dominance rough set approach proposed in this paper can improve the accuracy and reasonableness of classifying the level of emergency communication, but it is mainly fit for the post-evaluation of emergency communication after accident occurs. In the future, we will focus on the dynamic classification model in the entire event and propose a dynamic emergency communication classification model by use of the system approach.

\section{Conflict of Interests}

The authors declare that there is no conflict of interests regarding the publication of this paper.

\section{Acknowledgments}

This work was supported in part by a grant from Society Science Foundation of China Ministry of Education (Grant no. 11YJA630016) and Society Science Foundation of China (Grant no. 12XGL015).

\section{References}

[1] W. Xiaoyu, S. Sanshan, and L. Anwen, "Discussion on the national emergency communication management of serious natural disaster," Journal of Chongqing University of Posts and Telecommunications (Social Science), vol. 1, pp. 29-34, 2009.

[2] Z. Pawlak, "Rough sets," International Journal of Computer and Information Sciences, vol. 11, no. 5, pp. 341-356, 1982.

[3] S. Greco, B. Matarazzo, and R. Slowinski, "Rough approximation of a preference relation by dominance relations," European Journal of Operational Research, vol. 117, no. 1, pp. 63-83, 1999.

[4] S. Greco, B. Matarazzo, and R. Slowinski, "Rough approximation by dominance relations," International Journal of Intelligent Systems, vol. 17, no. 2, pp. 153-171, 2002.

[5] S. Greco, B. Matarazzo, and R. Slowinski, "Rough sets theory for multicriteria decision analysis," European Journal of Operational Research, vol. 129, no. 1, pp. 1-47, 2001.

[6] S. Greco, B. Matarazzo, and R. Slowinski, "On joint use of indiscernibility, similarity and dominance in rough approximation of decision classes," Research Report RA-012/98, Institute of Computing Science, Poznan University of Technology, Poznan, Poland, 1998, Proceedings of the 5th International Conference of the Decision Science Institute, pp. 1380-1382, Athens, Greece, July 1999. 
[7] Z. Pawlak, "Rough sets," in Rough Sets and Data Mining: Analysis for Imprecise Data, T. Y. Lin and N. Cercone, Eds., Kluwer Academic Publishers, Norwell, Mass, USA, 1997.

[8] S. Greco, B. Matarazzo, and R. Slowinski, "Rought sets theory for multicriteria decision analysis," European Journal of Operational Research, vol. 129, no. 1, pp. 1-47, 2001.

[9] S. Greco, B. Matarazzo, and R. Slowinski, "A new rough set approach to evaluation of bankruptcy risk," in Rough Fuzzy and Fuzzy Rough Sets, C. Zopounidis, Ed., pp. 121-136, Kluwer Academic Publishers, Dordrecht, The Netherlands, 1998.

[10] J. J. H. Liou and G.-H. Tzeng, "A dominance-based rough set approach to customer behavior in the airline market," Information Sciences, vol. 180, no. 11, pp. 2230-2238, 2010.

[11] Ministry of Industry and Information Technology of the People's Republic of China, The National Emergency Preplans for Communication Assurance, 2011.

[12] F.-C. Kong, "Construction of gradation model of library crisis events," Library and Information Work, vol. 13, pp. 42-45, 2009.

[13] Q. Wang, W. Yi, X.-D. Tian, J.-Y. Wang, and W. Xiao, "Study on prototype model on classification of response-level during carrier emergency telecommunications," Modern Science Technology of Telecommunications Z, vol. 1, pp. 60-64, 2012.

[14] H. Hu, Burst Communication Engineering Progress Control, Beijing University of Posts and Telecommunications, 2010.

[15] L. Chen, Research on Large-Scale Emergency Communications Management System and Its Application, Beijing University of Posts and Telecommunications, Beijing, China, 2012.

[16] F. Wang, J. Li, and Y.-H. Shi, "Fuzzy comprehensive assessment model and application of traffic grade on emergency in city," Journal of Hebei University (Natural Science), vol. 1, pp. 61-64, 2013.

[17] J. Liu and J. M. Chen, "A multi-stage dynamic and fuzzy classification algorithm and application in emergency management," Management Review, vol. 19, no. 3, pp. 38-43, 2007.

[18] J. Yang, J.-M. Chen, and H. Zhao, “The classification of emergency in incident management," Management Review, vol. 4, pp. 37-41, 2005.

[19] G.-H. Wang and A. Chen, "Research on the design of the emergency start mechanism," Journal of UESTC (Social Science Edition), vol. 4, pp. 44-48, 2012.

[20] Y.-L. Liu, S.-Y. Xu, J. Wang, C.-N. Xie, B.-B. Hu, and Q.-L. Zhao, "Research on the present status of disaster data and information sharing at home and abroad," Journal of Catastrophology, vol. 3, pp. 109-113, 2008. 


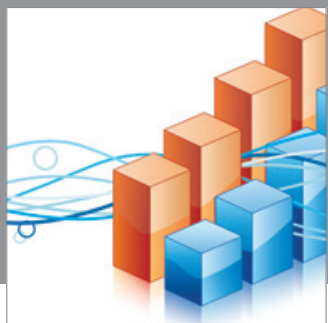

Advances in

Operations Research

mansans

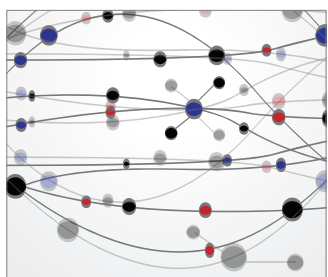

The Scientific World Journal
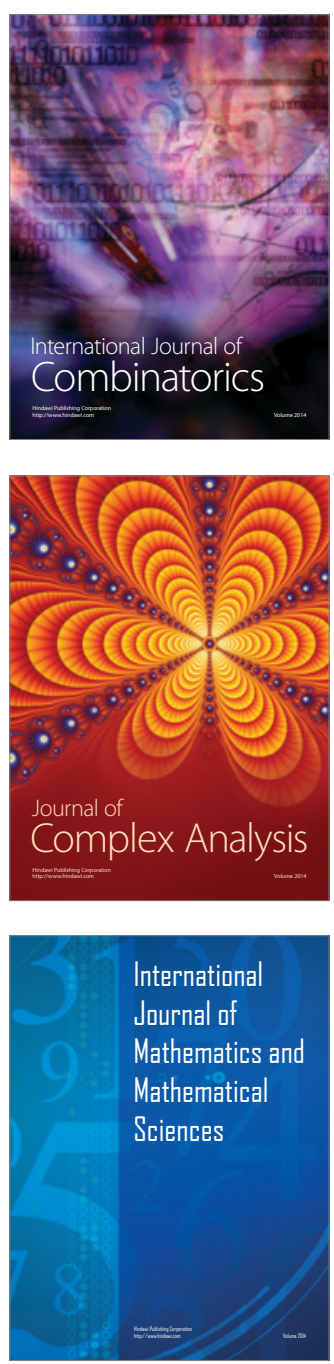
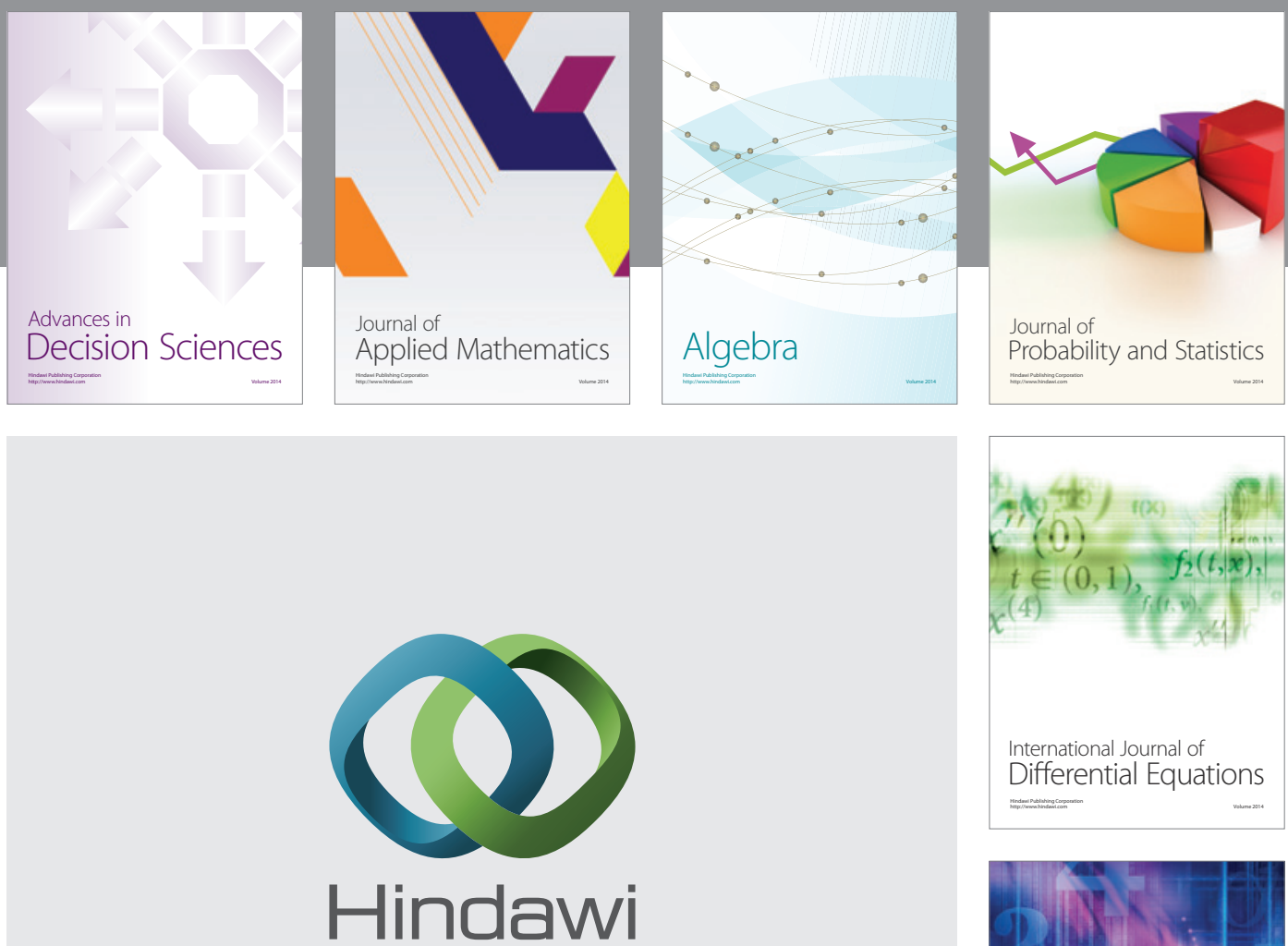

Submit your manuscripts at http://www.hindawi.com
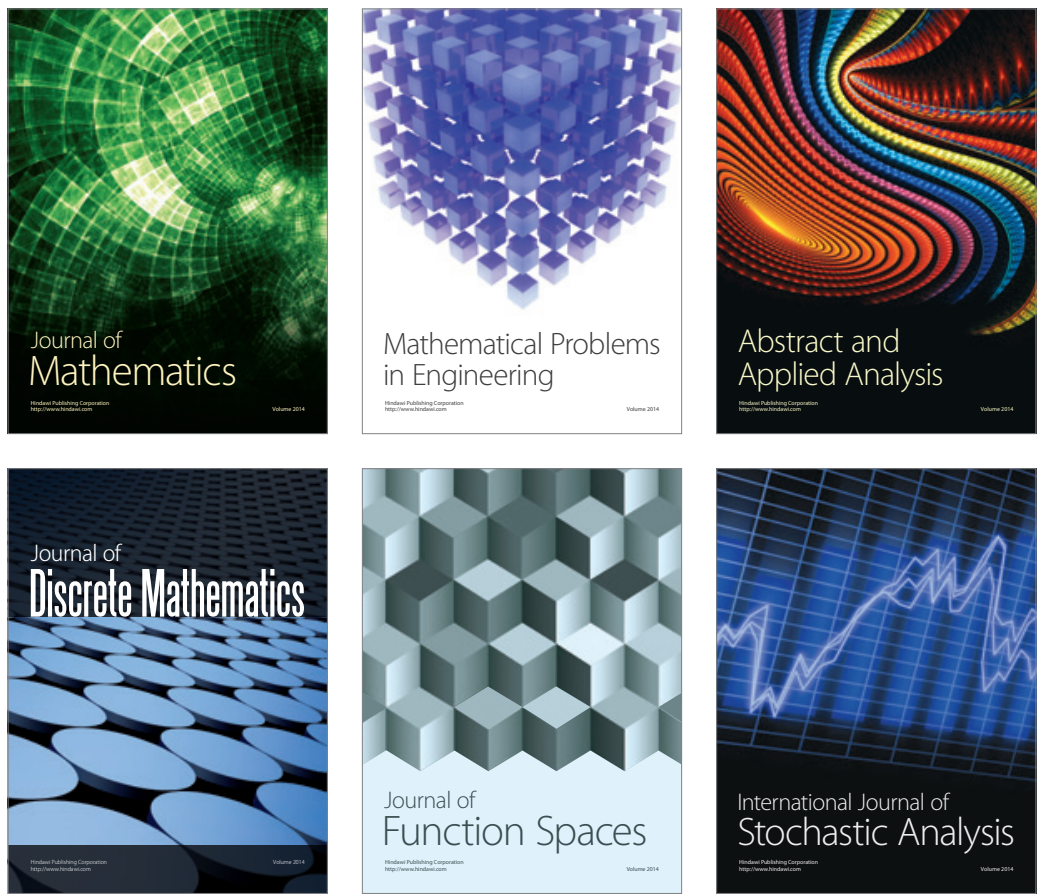

Journal of

Function Spaces

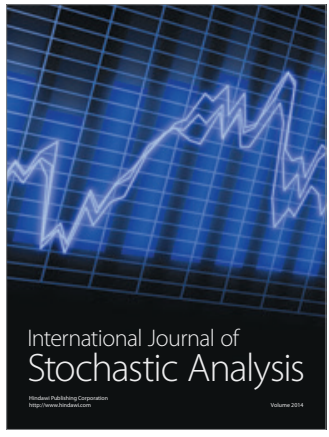

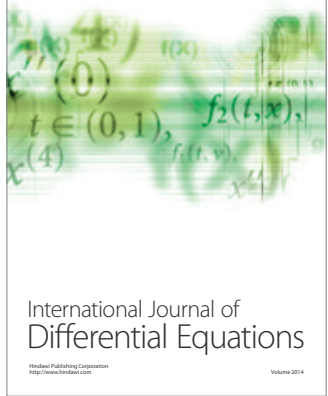
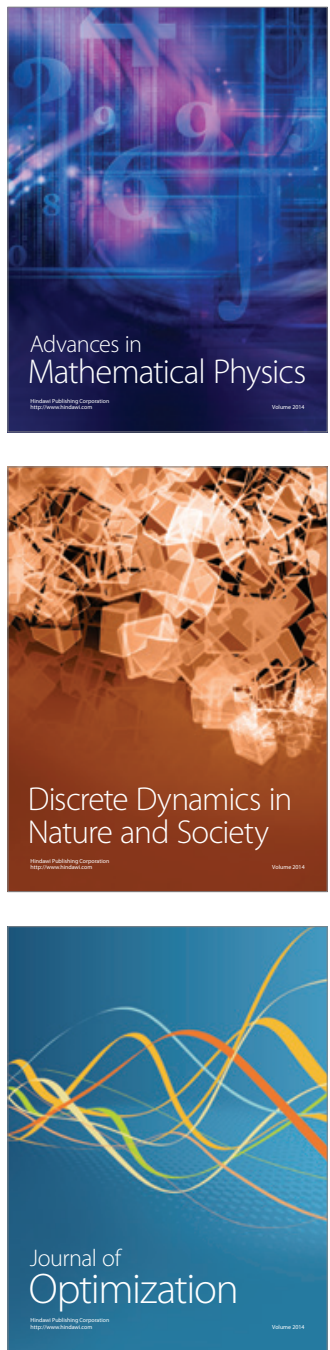